\title{
Evaluation of a non-ablative Er: YAG laser procedure to increase the oropharyngeal airway volume: A pilot study
}

\author{
Cameron Y. S. Lee ${ }^{1 *}$ and Cameron C. Y. Lee ${ }^{2}$ \\ ${ }^{1}$ Private Practice in Oral, Maxillofacial and Reconstructive Surgery \\ ${ }^{2}$ Harvard School of Dental Medicine, 188 Longwood Avenue, Boston, USA
}

\begin{abstract}
Background: Sleep disordered breathing, specifically obstructive sleep apnea (OSA) is due to constriction of the oropharyngeal airway during sleep and has major public health implications. By conservative estimates, $3 \%$ of the adult population are suffering from OSA characterized by sleep deprivation, fatigue during the day and somnolence. The most common treatment for sleep apnea is continuous positive airway pressure (CPAP). However, CPAP does not eliminate the cause of OSA.

Methods: The goal of this prospective pilot study was to evaluate the changes of the total airway volume and most constricted area of the oropharyngeal airway using a non-ablative laser procedure. Cone beam computed tomography (CBCT) scans were obtained from seven patients enrolled in the study. Airway volume measurements were calculated before and after laser treatment using $3 \mathrm{D}$ volumetric software.
\end{abstract}

Results: The photothermic effects of a non-ablative laser procedure increased the mean total airway volume from $10.23 \pm 0.94 \mathrm{~mL}$ to $12.54 \pm 1.01 \mathrm{~mL}(p=0.0179)$, and the minimum cross-sectional area from $109.7 \pm 20.6 \mathrm{~mm}^{2}$ to $142.4 \pm 29.2 \mathrm{~mm}^{2}(p=0.0484)$ approximately 12 weeks post-laser treatment.

Conclusions: Non-ablative laser therapy may be a promising non-surgical treatment modality for increasing the oropharyngeal airway volume, especially the most constricted area.

Clinical implications: The results of this pilot study demonstrate that photothermal energy applied to the pharyngeal and palatal soft tissues may prove to be beneficial in the non-surgical management of sleep disordered breathing, especially the CPAP intolerant individual.

\section{Introduction}

Sleep disordered breathing affects thousands of adults and children in the United States $[1,2]$. Symptoms produced by snoring and apnea are the result of either partial or total collapse of the upper respiratory airway tract during sleep [3]. Anatomic structures involved may include the soft palate, tonsils, uvula, base of tongue and lateral pharyngeal walls [4]. In these patients, the airway caliber is decreased by soft tissue excess and negative airway pressure. Obstructive sleep apnea (OSA) leads to morbidity and mortality [1-4].

Various treatment modalities for sleep disordered breathing have been recommended in the treatment of OSA. The goal is to decrease the amount of soft tissues in the pharynx [5]. This can be accomplished by non-surgical interventions, such as weight reduction, avoiding the use of alcohol and sedatives at night, continuous positive airway pressure (CPAP), and use of oral mandibular appliances to move the tongue base anteriorly. However, many clinicians do not know how to precisely advance the mandible in a protrusive and downward direction to effectively relieve the obstruction of the pharynx [6].

Surgery may also indicate, such as surgical advancement of the maxilla and mandible, either separately or combined is the accepted treatment of OSA [7,8]. Maxillary advancement via Le Forte I osteotomy increases the nasopharyngeal airway volume in Class III dentofacial skeletal patients. Two jaw surgeries consisting of maxillary and mandibular advancement surgery is effective when the goal is to increase the pharyngeal airway at different levels to relieve obstruction. This is the most effective invasive surgical procedure, with an $86 \%$ improvement for OSA [9]. Mandibular advancement surgery via bilateral sagittal split ramus osteotomies enlarges the pharyngeal airway, and is the focus of many studies regarding mandibular repositioning. However, the precise outcome from single jaw surgery to relieve OSA has not been determined $[10,11]$. Advanced surgical techniques in the treatment of sleep apnea may include laser-assisted uvulopalatoplasty and radiofrequency palatal reduction. Both methods decrease the palatal soft tissue volume and tissue collapsibility by increasing muscle tension as a result of the wound healing process [5].

Laser therapy does increase wound healing by facilitating the repair process by increasing vascular formation (neo-angiogenesis) and production of elastin, collagen, fibroblasts and epithelial tissues (neo-collagenesis) [12]. In non-ablative skin rejuvenation using laser treatment, Goldberg and Whitworth [13] reported satisfactory results in the treatment of periocular and perioral rhytides using a Q-switched $1,064 \mathrm{~nm}$ Nd: YAG laser. In another study using histology, Goldberg [14] demonstrated the benefits of Nd: YAG laser therapy on collagen remodeling. A Nd: YAG laser of 1,320 $\mathrm{nm}$ was used on the human

Correspondence to: Cameron Y. S. Lee, 98-1247 Kaahumanu Street, Suite 314, Aiea, Hawaii-96701, Tel: 808-484-2288; Fax: 808-484-1181; E-mail: CLee555294@aol.com

Key words: sleep disordered breathing, airway constriction, photothermic, nonablative laser procedure, cone beam computed tomography $(C B C T)$, oropharyngeal airway volume

Received: May 03, 2015; Accepted: June 08, 2015; Published: June 11, 2015 
skin comprising 8 treatments over six weeks and using histological methods. Trelles et al. [15] demonstrated that there was an increase in the number and density of collagen fibers during the remodeling phase. Further, the study revealed that with laser therapy there was a decrease in the interfibrillary space and excellent linear orientation of the remodeled collagen fibers. Other studies using the long pulsed $1064 \mathrm{~nm} \mathrm{Nd}$ : YAG laser on skin wrinkles showed an improvement in appearance that appeared to reduce skin laxity due to collagen remodeling [16-19]. The major effects of laser energy are applied externally and must penetrate the skin to reach their target tissues. The result is new collagen formation the results in retraction of skin [1219].

The use and results of laser treatment stimulate potential indications for a non-ablative laser procedure for sleep disordered breathing, such as snoring and sleep apnea. In a study involving 57 patients by Miracki and Vizintin [20] using an Er: YAG laser (Nightlase treatment) in noncontact mode, laser energy was applied to the soft palate and lateral pharyngeal walls of the pharynx. Laser parameters of the photothermic treatment were not included in their published study. Based on a questionnaire answered by the patients sleep partners, the authors concluded that there was an improvement in snoring and other sleep disordered breathing (SDB) symptoms.

To date, there are no published studies in the English literature utilizing a non-ablative laser procedure and what photothermic effects have on the pharyngeal airway. Pre- and post- treatment total airway volume changes and area of maximum constriction of the oropharyngeal airway were calculated using $3 \mathrm{D}$ volumetric software. The goal of this prospective pilot study was to evaluate if a non-ablative laser procedure using an Er: YAG laser will increase the oropharyngeal airway volume, especially the maximum area of constriction.

\section{Obstructive sleep apnea and cone beam computed tomography (CBCT)}

In the OSA patient, pharyngeal obstruction mostly occurs in the oropharynx [21]. Measuring changes in the most constricted area (minimal cross section), because of collapsibility of the pharynx is regarded as the best parameter to measure treatment outcomes [22]. Prior to the introduction of cone beam computed tomography (CBCT), very little information could be obtained from the use of conventional imaging studies, such as lateral cephalometric radiographs to evaluate treatment of the OSA patient [23]. With CBCT and the various three dimensional (3D) software programs now available to visualize and measure the hard and soft tissue volume of the maxillofacial region, it is now possible to evaluate and accurately measure airway volume of the pharynx as a response to treatment in the OSA patient. The greatest advantage of CBCT over conventional radiographs is the ability to visualize the pharyngeal airway obtained from axial views, which are perpendicular to the direction of airflow [24-29].

From studies reported in the literature, $\mathrm{CBCT}$ and the $3 \mathrm{D}$ computer software programs are able to measure airway volume from the nose to the pharynx before and after oral and maxillofacial surgery [24-28]. Semiautomated and fully automated software programs are available that can calculate the area, volume and other areas of interest of the pharyngeal airway and display the results virtually. In this prospective study, to evaluate the changes on airway volume of the pharynx after laser treatment, measurement of the oropharyngeal airway volume and minimum cross sectional area will be performed using $\mathrm{CBCT}$ and a 3D software (Anatomage Tx Studio, San Jose, CA).

\section{Materials and methods}

This prospective study consisted of seven patients $(5$ men and 2 women) who presented to the private practice of one of the authors (CYSL). Average age of all participants was 59.5 years (Table 1). Of the seven patients, 5 patients had been diagnosed with OSA from a sleep center. The remaining two patients were documented snorers and suspected of having OSA from family members. Each patient completed a non-ablative laser procedure that consisted of four sessions, two weeks apart over an eight week period. Informed consent was obtained prior to initiating treatment.

Skeletal muscle is a highly specialized structure that consists of long, parallel multinucleated myotubes that functions in contraction [30]. The soft palate consists of five pairs of muscles: tensor veli palatini, levator veli palatini, palatopharyngeus, palatoglossus, and the uvulae [31]. For the clinician during the laser procedure, the oropharyngeal anatomical structures that are lasered are the palatoglossal arch, palatopharyngeal arch and uvula. During each office procedure, the anatomical structures are lasered six times in precise fashion with overlapping of the laser beam, as the laser is advanced from one anatomic area to the next. Spot size of the laser beam is $10.0 \mathrm{~mm}$ and the tip of the laser hand piece is placed approximately 20.0 to $25.0 \mathrm{~mm}$ away from the target tissue. Using the Er: YAG laser (Lightwalker laser, Technology4Medicine, Irvine, CA) having an infrared of wavelength $2940 \mathrm{~nm}$, the parameters were set to the following: Variable Pulse Laser Mode at $500 \mathrm{~mJ} ; 6 \mathrm{~Hz} ; 3 \mathrm{~W}$.

Pre-laser СBCT scans were completed prior to initiating laser therapy to obtain values of the pharyngeal airway volume and minimum cross sectional area (most constricted). Post-laser CBCT scans were completed at the completion of laser treatment at an average of 81 days after the last laser treatment, for a total of two CBCT scans.

\section{Image acquisition}

The method for pre-laser and post-laser CBCT image acquisition and analysis in this project utilizes the iCAT Classic system (Imaging Sciences International, Hatfield, PA), with the following protocol: a 47.7 $\mathrm{mA}, 120 \mathrm{kVp}, 20$ seconds scan time and a voxel of $0.4 \mathrm{~mm} \times 0.4 \mathrm{~mm}$ x $0.4 \mathrm{~mm}$. A 13 inch field of view was used in this imaging protocol that included the entire maxillofacial anatomy. All patients were upright and sitting with their head in a natural position. Teeth were positioned in maximum intercuspation and the tip of the tongue touching the lingual surfaces of the incisor teeth. Patients were instructed not to swallow and breathe normally.

\section{Software analysis}

Digital image files of the patients were exported in digital imaging and communications in medicine (DICOM) format and processed using the Tx Studio software (Anatomage, version 5.2, San Jose, CA). All images were converted into volumetric images and reconstructed sagittal, axial and coronal slices. In measuring airway volume of the pharynx, superior and inferior borders were designated, hard and soft tissue anatomic landmarks. The superior border of the pharyngeal airway was designated as the line drawn through the palatal plane (ANS to PNS) to basion, which is the most posterior-inferior point of the front edge of the foramen magnum. The inferior border was defined as the line drawn from the vallecula $(\mathrm{V})$ to the inferior surface of the third cervical vertebrae (C3).

Pharyngeal airway volume was based on the software manufacturer (Tx Studio, version 5.2 reference manual, Anatomage) instructions 
[32]. With this software, the clinician must outline the specified airway volume of interest using a computer mouse. Once the airway volume has been designated based on the superior and inferior borders, the software program will automatically calculate the total airway volume (in $\mathrm{mL}$ ), as well as the minimum cross-sectional area, which is the most constricted part of the pharyngeal airway using color coded constriction values (Figure 1). This method of measuring airway volume is considered consistent and stable, as cervical vertebrae were used as anatomic reference landmarks.

The paired t-test was used to evaluate changes in total airway volume and minimal cross sectional area before and after surgery. Simple linear regression was used to evaluate post-operative changes in airway parameters with respect to time. Data are presented as mean \pm standard error. $\mathrm{P}$ values less than 0.05 were considered statistically significant. Statistical analysis was performed using Graphpad Prism 6.0 software (Graphpad, La Jolla, CA).

\section{Results}

Laser treatment increased the mean total airway volume from 10.23 $\pm 0.94 \mathrm{~mL}$ to $12.54 \pm 1.01 \mathrm{~mL}(p=0.0179)$, and the minimum crosssectional area from $109.7 \pm 20.6 \mathrm{~mm}^{2}$ to $142.4 \pm 29.2 \mathrm{~mm}^{2}(p=0.0484)$. The data clearly demonstrate that the oropharyngeal airway volume was significantly increased as a result of the photothermc effects from the non-ablative laser procedure (Figures $2 \mathrm{~A}$ and $2 \mathrm{~B}$ ). Total airway volume increased by $22.6 \%$, and the minimum constricted area, $29.8 \%$.

\section{Discussion}

The goal of this study was to evaluate if the photothermic effects of a non-ablative laser procedure could increase the total volume and minimum cross sectional area of the oropharyngeal airway. Use of $\mathrm{CBCT}$ to obtain three-dimensional (3D) imaging of the upper airway is now becoming the imaging standard to evaluate anatomic constrictions in patients with sleep disordered breathing [24-29]. To the author's knowledge, this is the first study in the world English literature of a non-ablative laser procedure that increased the oropharyngeal airway volume, including the minimum constricted area using CBCT volumetric data. Measuring the $3 \mathrm{D}$ airway volume changes using $\mathrm{CBCT}$

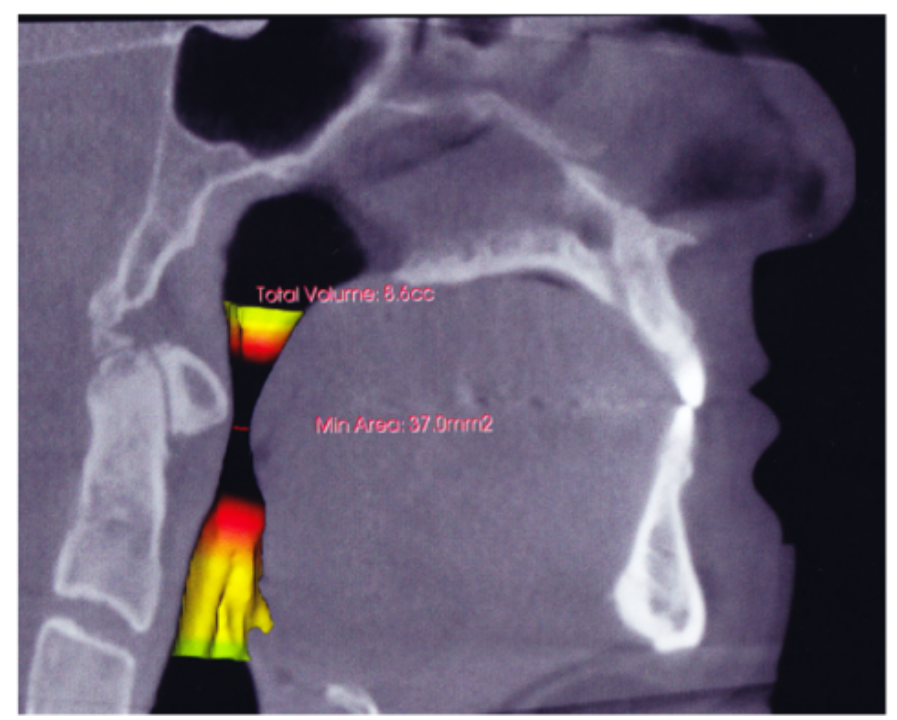

Figure 1. Sagittal cone beam CT scan with use of 3D imaging software of patient in sagitta view demonstrating area of minimum constriction (arrow) of oropharynx prior to laser treatment.
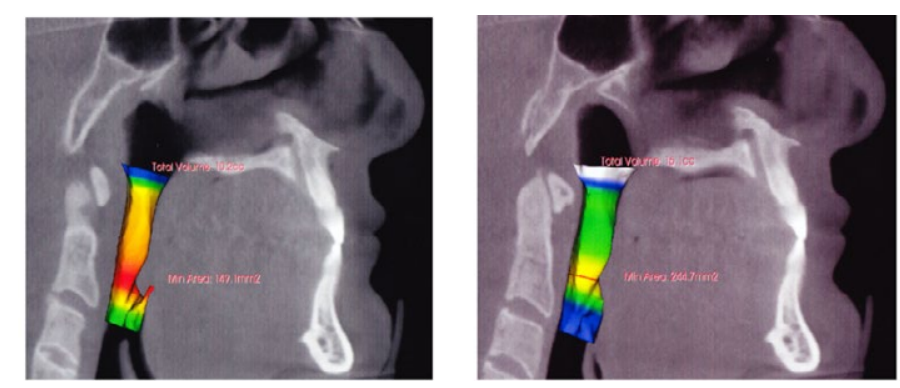

Figure 2. Airway volume a) Before and b) After. Volumetric assessment of patient's airway using sagittal cone beam computed tomography image and Anatomage's Tx Studio software before and after non-ablative laser treatment. Note the increase in both total volume and area of minimum constriction after laser treatment.

at the most constricted cross-sectional area of the pharyngeal airway is important, as it provides the clinician with information regarding efficacy of treatment, as the majority of obstructions in the OSA patient occur in the oropharynx [21].

To the author's knowledge, there are no published articles in the dental and medical literature describing the effects of laser treatment on the oropharyngeal airway, specifically collagen which possesses different biomechanical properties, based on function. Type I collagen is observed in the dermis, bone and tendons [33]. Adult skin is composed of $80-85 \%$ type I collagen, and $10-15 \%$ type III collagen. Type III collagen is found in the uterus and fetal dermis. It is the dominant collagen in fetal skin [33,34]. As the skin ages during the adult years, there is a gradual replacement of fetal collagen with type I collagen. In a mouse study by Liu et al. [12] evaluating the effects of laser energy on dermal remodeling, histological studies revealed that three weeks after laser treatment, there was an observed increase in fibroblast proliferation and collagen synthesis of both type I and III after four laser treatments using an Nd: YAG laser. They concluded that collagen remodeling and synthesis was due to the laser temperature effects inside the lower dermis responsible for skin tightening.

Of the seven patients participating in this pilot study, one patient (JF) experienced a decrease in pharyngeal airway volume and essentially no change in the area of minimum constriction after 38 days. However, the other six patients did experience an increase in total airway volume and in the area of minimum constriction. How the photothermic effects of the laser treatment accomplishes these remains unclear. We hypothesize that collagen specificity in the soft palate and pharyngeal walls may play an important role in decreasing the soft tissue collapsibility of the pharyngeal airway. Such increased hyperthermia to induce collagen tension is possible, as type I collagen is found in tissues that undergo high tension [5]. The observed findings in this study may also be due to an increase in collagen production that reduces soft tissue collapsibility of the pharyngeal airway. Although the results of this study have demonstrated that airway enlargement does occur from the photothermic effects of laser treatment, it is not known how long the increase in airway volume remains for each of our patients.

\section{Limitations of the study}

Our pilot study does have limitations. As only seven patients were included in this study, additional trials with larger sample sizes are needed to determine the efficiency of laser treatment. Another limitation of this study is that no histology was performed to evaluate the laser-tissue effects on the soft tissues of the pharynx. Histology studies may be indicated to reveal the exact mechanism of airway 
volume enlargement due to non-ablative laser therapy. Lastly, animal studies do provide support for observed in-vivo studies, but are unable to provide established parameters in humans.

\section{Conclusion}

The results of this pilot study demonstrate that photothermal energy applied to the pharyngeal and palatal soft tissues may be beneficial in the non-surgical treatment of sleep disordered breathing, especially the CPAP intolerant individual. The advantage of this laser procedure is the non-ablative method on collagen. Wound healing from laser treatment may result in the production of new type I collagen and collagen remodeling [12-19].

An important research question that needs to be addressed is if the laser-tissue effects observed from this prospective study on the pharyngeal airway has any benefit to the OSA patient. Our study did not attempt to correlate the findings of increased pharyngeal airway volume and the potential benefit to the OSA patient. A future study is planned that will include the use of polysomnography to evaluate the benefits of this laser technique for the OSA patient.

\section{Financial disclosure}

The authors have no financial interest in the products mentioned in this article.

\section{References}

1. A report of the National Commission on Sleep Disorders Research (1995) Wake Up America: A National Sleep Alert. Washington, D.C.: U. S. Government Printing Office.

2. Young T, Peppard PE, Gottlieb DJ (2002) Epidemiology of obstructive sleep apnea: a population health perspective. Am J Respir Crit Care Med 165: 1217-1239. [Crossref]

3. Lattimore JD, Celermajer DS, Wilcox I (2003) Obstructive sleep apnea and cardiovascular disease. J Am Coll Cardiol 41: 1429-1437. [Crossref]

4. Courey MS, Fomin D, Smith T, Huang S, Sanders D, et al. (1999) Histologic and physiologic effects of electrocautery, $\mathrm{CO} 2$ laser, and radiofrequency injury in the porcine soft palate. Laryngoscope 109: 1316-1319. [Crossref]

5. Fomin D, Nicola E, Oliver C, Farci M, Dibbern R, et al. (2007) Collagen type analysis in the soft palate after surgical intervention with $\operatorname{CO}(2)$ laser and radiofrequency ablation. Photomed Laser Surg 25: 449-454. [Crossref]

6. Haskella JA, McCrillisb J, Haskellc BS, Scheetzd JP, Scarfee WC, et al. (2009) Effects of mandibular advancement device (MAD) on airway dimensions assessed with conebeam computed tomography. Semin Orthod 15:132-158.

7. Mehra P, Downie M, Pita MC, Wolford LM (2001) Pharyngeal airway space changes after counterclockwise rotation of the maxillomandibular complex. Am J Orthod Dentofacial Orthop 120: 154-159. [Crossref]

8. Abramson Z, Susarla SM, Lawler M, Bouchard C, Troulis M, et al. (2011) Threedimensional computed tomographic airway analysis of patients with obstructive sleep apnea treated by maxillomandibular advancement. J Oral Maxillofac Surg 69: 677-686. [Crossref]

9. Holty JE, Guilleminault C (2010) Maxillomandibular advancement for the treatment of obstructive sleep apnea: a systematic review and meta-analysis. Sleep Med Rev 14: 287-297. [Crossref]

10. Foltán R, Hoffmannová J, Pavlíková G, Hanzelka T, Klíma K, et al. (2011) The influence of orthognathic surgery on ventilation during sleep. Int J Oral Maxillofac Surg 40: 146-149. [Crossref]

11. Hernández-Alfaro F, Guijarro-Martínez R, Mareque-Bueno J (2011) Effect of monoand bimaxillary advancement on pharyngeal airway volume: cone-beam computed tomography evaluation. J Oral Maxillofac Surg 69: e395-400. [Crossref]

12. Liu H, Dang Y, Wang Z, Chai X, Ren Q (2008) Laser induced collagen remodeling: a comparative study in vivo on mouse model. Lasers Surg Med 40: 13-19. [Crossref]

13. Goldberg DJ, Whitworth J (1997) Laser skin resurfacing with the Q-switched Nd:YAG laser. Dermatol Surg 23: 903-906. [Crossref]

14. Goldberg DJ, Silapunt S (2000) Q-switched Nd:YAG laser: rhytid improvement by non-ablative dermal remodeling. J Cutan Laser Ther 2: 157-160. [Crossref]

15. Trelles MA, Allones I, Luna R (2001) Facial rejuvenation with a nonablative $1320 \mathrm{~nm}$ Nd:YAG laser: a preliminary clinical and histologic evaluation. Dermatol Surg 27: 111-116. [Crossref]

16. Rogachefsky AS, Becker K, Weiss G, Goldberg DJ (2002) Evaluation of a long-pulsed $\mathrm{Nd}$ :YAG laser at different parameters: an analysis of both fluence and pulse duration. Dermatol Surg 28: 932-935. [Crossref]

17. Dayan S, Damrose JF, Bhattacharyya TK, Mobley SR, Patel MK, et al. (2003) Histological evaluations following 1,064-nm Nd:YAG laser resurfacing. Lasers Surg Med 33: 126-131. [Crossref]

18. Dayan SH, Vartanian AJ, Menaker G, Mobley SR, Dayan AN (2003) Nonablative lase resurfacing using the long-pulse (1064-nm) Nd:YAG laser. Arch Facial Plast Surg 5: 310-315. [Crossref]

19. Trelles MA, Alvarez X, Martín-Vázquez MJ, Trelles O, Velez M, et al. (2005) Assessment of the efficacy of nonablative long-pulsed 1064-nm Nd:YAG laser treatment of wrinkles compared at 2, 4, and 6 months. Facial Plast Surg 21: 145-153. [Crossref]

20. Miracki K, Vizintin Z (2013) Nonsurgical minimally invasive Er: YAG laser snoring treatment. $J$ Laser and Health Academy 1:36-41.

21. Ogawa T, Enciso R, Shintaku WH, Clark GT (2007) Evaluation of cross-section airway configuration of obstructive sleep apnea. Oral Surg Oral Med Oral Pathol Oral Radiol Endod 103: 102-108. [Crossref]

22. Valladares-Neto J, Silva MAG, Bumann A (2013) Effects of mandibular advancement surgery combined with minimal maxillary displacement on the volume and most restricted cross-sectional area of the pharyngeal airway. Int J Oral Maxillofac Surg 42: 1437-1445. [Crossref]

23. Aboudara C, Nielsen I, Huang JC, Maki K, Miller AJ, et al. (2009) Comparison of airway space with conventional lateral headfilms and 3-dimensional reconstruction from cone-beam computed tomography. Am J Orthod Dentofacial Orthop 135: 468479. [Crossref]

24. Fairburn SC, Waite PD, Vilos G, Harding SM, Bernreuter W, et al. (2007) Threedimensional changes in upper airways of patients with obstructive sleep apnea following maxillomandibular advancement. J Oral Maxillofac Surg 65: 6-12. [Crossref]

25. Osorio F, Perilla M, Doyle DJ, Palomo JM (2008) Cone beam computed tomography: an innovative tool for airway assessment. Anesth Analg 106: 1803-1807. [Crossref]

26. Abramson ZR, Susarla S, Tagoni JR, Kaban L (2010) Three-dimensional computed tomographic analysis of airway anatomy. J Oral Maxillofac Surg 68: 363-371. [Crossref]

27. El H, Palomo JM (2010) Measuring the airway in 3 dimensions: a reliability and accuracy study. Am J Orthod Dentofacial Orthop 137: S50. [Crossref]

28. Schendel SA, Hatcher D (2010) Automated 3-dimensional airway analysis from conebeam computed tomography data. J Oral Maxillofac Surg 68: 696-701. [Crossref]

29. Isono S, Morrison DL, Launois SH, Feroah TR, Whitelaw WA, et al. (1993) Static mechanics of the velopharynx of patients with obstructive sleep apnea. $J$ Appl Physiol (1985) 75: 148-154. [Crossref]

30. Zhao Y, Zeng H, Nam J, Agarwal S (2009) Fabrication of skeletal muscle constructs by topographic activation of cell alignment. Biotechnol Bioeng 102: 624-631. [Crossref]

31. Carvajal Monroy PL, Grefte S, Kuijpers-Jagtman AM, Wagener FA, Von den Hoff JW (2012) Strategies to improve regeneration of the soft palate muscles after cleft palate repair. Tissue Eng Part B Rev 18: 468-477. [Crossref]

32. Tx Studio 5.2. Reference manual (2013) Anatomage. San Jose, CA

33. Sweat F, Puchtler H, Rosenthal Si (1964) Sirius Red F3BA as a stain for connective tissue. Arch Pathol 78: 69-72. [Crossref]

34. Junqueira LC, Cossermelli W, Brentani R (1978) Differential staining of collagens type I, II and III by Sirius Red and polarization microscopy. Arch Histol Jpn 41: 267-274. [Crossref]

Copyright: (C2015 Lee CYS. This is an open-access article distributed under the terms of the Creative Commons Attribution License, which permits unrestricted use, distribution, and reproduction in any medium, provided the original author and source are credited. 